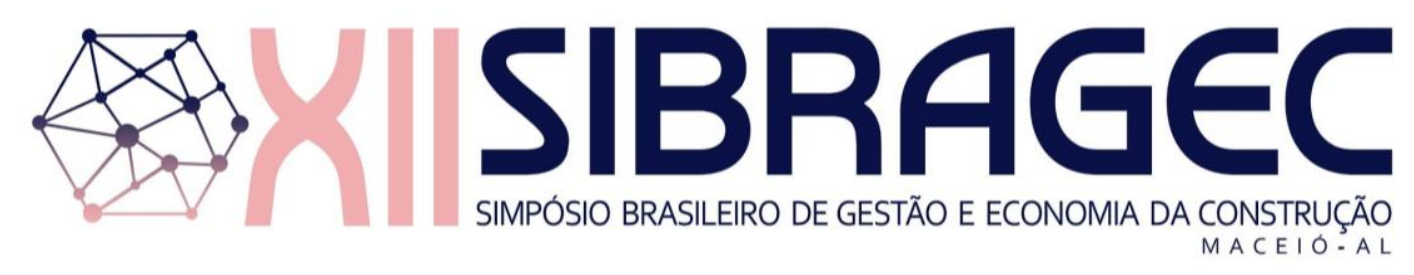

\title{
ANÁLISE DE FLUXOS DE CANTEIRO DE OBRAS PELO USO DO DIAGRAMA ESPAGUETE ${ }^{1}$
}

\author{
AMARAL, Camila Marcantonio (1); COSTA, Eliane Betânia Carvalho (2) \\ (1) Universidade Federal de Uberlândia, camila_mamaral@ hotmail.com (2) Universidade Federal \\ de Uberlândia, elianebetania@ufu.br
}

\begin{abstract}
RESUMO
O planejamento, a implantação e a gestão do canteiro de obras, muitas vezes negligenciados, é de extrema importância para a produtividade. A otimização do fluxo de pessoas, materiais e equipamentos contribui para a redução das atividades que não agregam valor e do tempo de ciclo de produção (lead time) minimizando custos, prazo e desperdícios. O presente trabalho tem como objetivo analisar a influência do arranjo físico nos fluxos de um canteiro de obras e propor melhorias pelo uso do diagrama espaguete. Para tal, foi feita a análise de um projeto de canteiro proposto para a execução de um galpão industrial e, posteriormente, foram propostas modificações no layout do canteiro, visando à redução da movimentação de materiais, equipamentos e mão de obra durante as etapas da obra. Para o traçado e a determinação do comprimento das linhas dos fluxos no diagrama espaguete foi utilizado o software Autocad®. Foram analisados os fluxos de entrega-armazenamento de materiais; de transporte dos perfis metálicos produção a instalação; retirada de entulho; execução da argamassa para alvenaria e revestimento; e do caminho percorrido até o banheiro. Os resultados mostraram que é possível observar reduções de movimentação de até $77 \%$ com a otimização de um dado fluxo.
\end{abstract}

Palavras-chave: Canteiro de obra, Arranjo físico, Planejamento, Diagrama Espaguete.

\begin{abstract}
Planning, implementation and management of construction site is often neglected but they are extremely important for productivity. The optimization of the flow of workers, materials and equipment contributes to the reduction of activities that do not add value and the lead-time reducing costs, deadlines and waste. The present work aims to analyze the influence of the site layout on the flows of a construction site and to propose improvements through the use of the spaghetti diagram. To this end, an analysis of a proposed project for the construction of an industrial building was carried out. Modifications were proposed in the layout of the site, aiming at reducing the movement of materials, equipment and labor during the stages of the work. Autocad® software was used for design and obtaining the length of the flow lines in the spaghetti diagram. Material delivery-storage flows were analyzed; transport of metal profiles - production to installation; removal of wastes; execution of mortar for masonry and coating; and the path taken to the bathroom. The results showed that it is possible to observe movement reductions of up to $77 \%$ with the optimization of a given flow.
\end{abstract}

Keywords: Construction site, Site layout, Planning, Spaghetti Diagram.

\section{INTRODUÇÃO}

O canteiro de obras é tido como uma tarefa independente das atividades tradicionalmente associadas a execução da construção. Segundo a NBR 12284 (ABNT, 1991) esse pode ser definido como o conjunto de "áreas destinadas à execução e apoio dos trabalhos da indústria da construção dividindo-se em áreas operacionais e áreas de vivência”.

\footnotetext{
${ }^{1}$ AMARAL, C. M.; COSTA, E. B. C. C. Análise de fluxos de canteiro de obras pelo uso do diagrama espaguete. In: SIMPÓSIO BRASILEIRO DE GESTÃO E ECONOMIA DA CONSTRUÇÃO, 12., 2021, Maceió. Anais[...] Porto Alegre: ANTAC, 2021. p.1-8. Disponível em: https://eventos.antac.org.br/index.php/sibragec/article/view/557. Acesso em: 2 out. 2021.
} 
Para Elbeltagi (2014) o planejamento do layout do canteiro de obras envolve a identificação, o dimensionamento e o posicionamento das instalações fixas e temporárias dentro dos limites do canteiro de obras. Vieira (2006) destaca a importância da logística na minimização dos fluxos de pessoas, materiais e equipamentos. A redução da movimentação e do transporte contribui para a redução das atividades que não agregam valor e do tempo de ciclo de produção (lead time), princípios da construção enxuta estabelecidos por Koskela (1993).

O planejamento, a implantação e a gestão do canteiro de obras muitas vezes é negligenciado, permitindo que as decisões sejam tomadas por tentativa e erro, improvisos ou ao acaso, condenando o empreendimento à desorganização, à improdutividade e ao desperdício (TOMMELEIN, 1994; SAURIN, FORMOSO, 2006; ELBELTAGI, 2014; POLITO, 2015; AGUIAR, 2016). Aguiar (2016), por meio de um questionário distribuído a gestores de obras em construtoras brasileiras, verificou que $74 \%$ das obras executadas não possuem procedimento ou plano formal com diretrizes para o planejamento do canteiro de obras; $12 \%$ não possuem um procedimento, mas possuem ferramentas que auxiliam o planejamento das partes; e somente 7\% dispõem de procedimentos ou planos que orientam no planejamento do canteiro de obras (layout, especificação e dimensionamento de soluções de movimentação e armazenamento de materiais).

A definição do layout de canteiro é um caso típico de alocação de espaço, e afeta diretamente a produtividade e a segurança. Algumas e ferramentas têm sido utilizadas para análise e otimização do arranjo físico, tais como o uso diagramas de processos, mapofluxogramas, algoritmos de otimização, simulações em BIM 4D (HERZAGY; ELBELTAGY, 2000; MELO; COSTA, 2015; VIANA et al., 2017 SACRAMENTO et al., 2019; COSTA; FERREIRA, 2019; CARVALHO; CAMPOS, 2019; XU et al. 2019; HAWARNEH; BENDAK; GHANIM, 2021). O diagrama espaguete é utilizada analisar os fluxos de materiais, pessoas, equipamentos numa dada área de trabalho, bastante utilizada para organização de escritórios, áreas de produção e hospitais, ainda pouco explorada no canteiro de obras.

Neste sentido, o presente trabalho tem como objetivo analisar a influência do arranjo físico na gestão de um canteiro de obras e propor ações de melhoria em função da redução dos deslocamentos de materiais, equipamentos e mão de obra pelo uso do diagrama espaguete. Essa ferramenta foi escolhida por ser simples e de fácil entendimento. Para isso, foram elaborados diagramas de fluxos de determinadas etapas da obra e proposto um traçado otimizado visando a redução de movimentação e, consequentemente, a produtividade no canteiro de obras.

\section{DIAGRAMA ESPAGUETE}

O diagrama espaguete é uma ferramenta de representação gráfica utilizada para exibir ou esboçar a movimentação de materiais, pessoas, equipamentos numa dada área de trabalho visando identificar quaisquer melhorias possíveis no fluxo envolvido (SULE, 2008). Este diagrama é obtido a partir do traçado de linhas de um ponto a outro identificando os fluxos por meio de cores distintas. A análise do diagrama permite identificar os comprimentos dos movimentos, número de movimentos, movimentos de sobreposição e cruzamento, e suas características de acordo com a classificação escolhida. Aplicando o resultado do diagrama, pode-se identificar movimentos ineficientes e áreas ineficazes, eliminar o número de funcionários e fazer alterações na organização do trabalho ou no layout do posto de trabalho (SENDERSKÁ et al., 2017). Essa identificação de movimentos ineficientes é feita quando há deslocamentos muito longos que podem sem reduzidos. A análise do fluxo de materiais, equipamentos e outros envolve a determinação da sequência mais efetiva de movimentação desses, pelas etapas necessárias dos processos envolvidos e a intensidade ou magnitude desses movimentos. Um fluxo efetivo significa que os 
materiais se movem progressivamente ao longo do processo, sempre avançando para a conclusão e sem desvios excessivos ou retrocesso (contrafluxo) (MUTHER; HALES, 2015).

\section{METODOLOGIA}

O estudo foi realizado a partir de um projeto de um galpão industrial localizado na cidade de Monte Carmelo - MG, sendo desenvolvido em três etapas, a saber: (1) caracterização da edificação e do canteiro de obras proposto por um profissional; (2) elaboração do diagrama espaguete, traçando os fluxos principais para execução da obra conforme projeto do canteiro disponibilizado; (3) proposta de otimização do arranjo físico proposto visando a redução dos deslocamentos de materiais, equipamentos e mão de obra.

\subsection{Caracterização da obra}

O galpão foi projetado em um terreno de esquina, situado entre duas avenidas, contendo $2000 \mathrm{~m}^{2}$ de área total e a área a ser construída de $790 \mathrm{~m}^{2}$. Este galpão tem como finalidade o descarregamento de caminhões, armazenamento intermediário de produtos não perecíveis e serviços logísticos em geral. O local é composto por doca para descarregamento de materiais, área de armazenamento, almoxarifado, sala de reunião, sala administrativa, copa e banheiros feminino e masculino. O projeto prevê galpão de estrutura mista, contendo tesouras e pilares pré-fabricados metálicos, e pilares de travamento pré-moldados em concreto em alternância com os metálicos. As fundações, baldrames e piso do galpão serão executados em concreto usinado. A vedação lateral e frontal será feita em alvenaria convencional, e o fechamento lateral superior e a cobertura serão de telha trapezoidal metálica. A duração da obra foi prevista para um período de seis meses, considerando desde os serviços preliminares até a entrega da obra. O canteiro foi projetado para uma única fase (abordagem estática), não havendo modificações do posicionamento dos elementos ao longo de todo o período de execução da obra a fim de evitar desmobilizações.

\subsection{Caracterização do canteiro de obras}

As informações do canteiro de obras foram extraídas a partir do projeto disponibilizado pelo profissional responsável pela elaboração e execução do empreendimento e layout inicial do canteiro (AGUIAR, 2018). A área disponível para implantação do canteiro equivale a $527 \mathrm{~m}^{2}$, contando com áreas de apoio e de vivência. Estas instalações foram projetadas visando atender os requisitos da NR 18 (MINISTÉRIO DA ECONOMIA, 2020). A área de vivência do projeto em questão dispõe de um container para escritório, um refeitório construído em estruturas e painéis metálicos, e um banheiro químico para cada sexo. As áreas de apoio são constituídas pelos elementos necessários para o armazenamento, montagem e manuseio de materiais. Os elementos das áreas de apoio são distribuídos em: estoque de estruturas metálicas, central de aço, central de argamassa e almoxarifado. Para o descarte de entulhos provenientes da obra, há duas caçambas com capacidade de $5 \mathrm{~m}^{3}$ cada. As dimensões e áreas $\left(\mathrm{em}^{2}\right.$ ) dos elementos estão indicadas no Quadro 1.

Quadro 1 - Dimensões dos elementos da área de vivência e apoio do projeto proposto para o canteiro

\begin{tabular}{|c|l|c|c|}
\hline Elementos & \multicolumn{1}{|c|}{ Elemento } & Dimensões (m) & Área $\left(\mathbf{m}^{2}\right)$ \\
\hline \multirow{4}{*}{ Áreas de vivência } & Escritório & $2,20 \times 6,00$ & 13,2 \\
\cline { 2 - 4 } & Refeitório & $4,50 \times 5,60$ & 25,2 \\
\cline { 2 - 4 } & WC Feminino & $1,20 \times 1,20$ & 1,44 \\
\cline { 2 - 4 } & WC Masculino & $1,20 \times 1,20$ & 1,44 \\
\hline \multirow{3}{*}{ Áreas de apoio } & Almoxarifado & $4,80 \times 4,25$ & 20,40 \\
\cline { 2 - 4 } & Central de Argamassa & $5,00 \times 10,0$ & 50,00 \\
\cline { 2 - 4 } & Estoque Metálica / Central de Aço & $15,8 \times 10,0$ & 158,0 \\
\hline
\end{tabular}

Fonte: Os autores 2021. 
O canteiro foi delimitado, em todo o seu entorno, por tapumes de madeira compensada de 2,80 $\mathrm{m}$ de altura. Além disso, foram implementadas duas entradas para os equipamentos, ambas de 4,0 m de largura, localizadas uma na rua e outra em uma das avenidas. A entrada pela avenida também foi destinada à entrada e saída dos funcionários. A saída de equipamentos e entulhos, de 4,0 m de largura, foi fixada ao lado oposto de uma das entradas, saindo diretamente pela outra avenida. O croqui, apresentado na Figura 1, indica a disposição de todos os elementos mencionados existentes no canteiro na fase de execução da obra.

Figura 1 - Croqui do canteiro de obras proposto para o galpão industrial

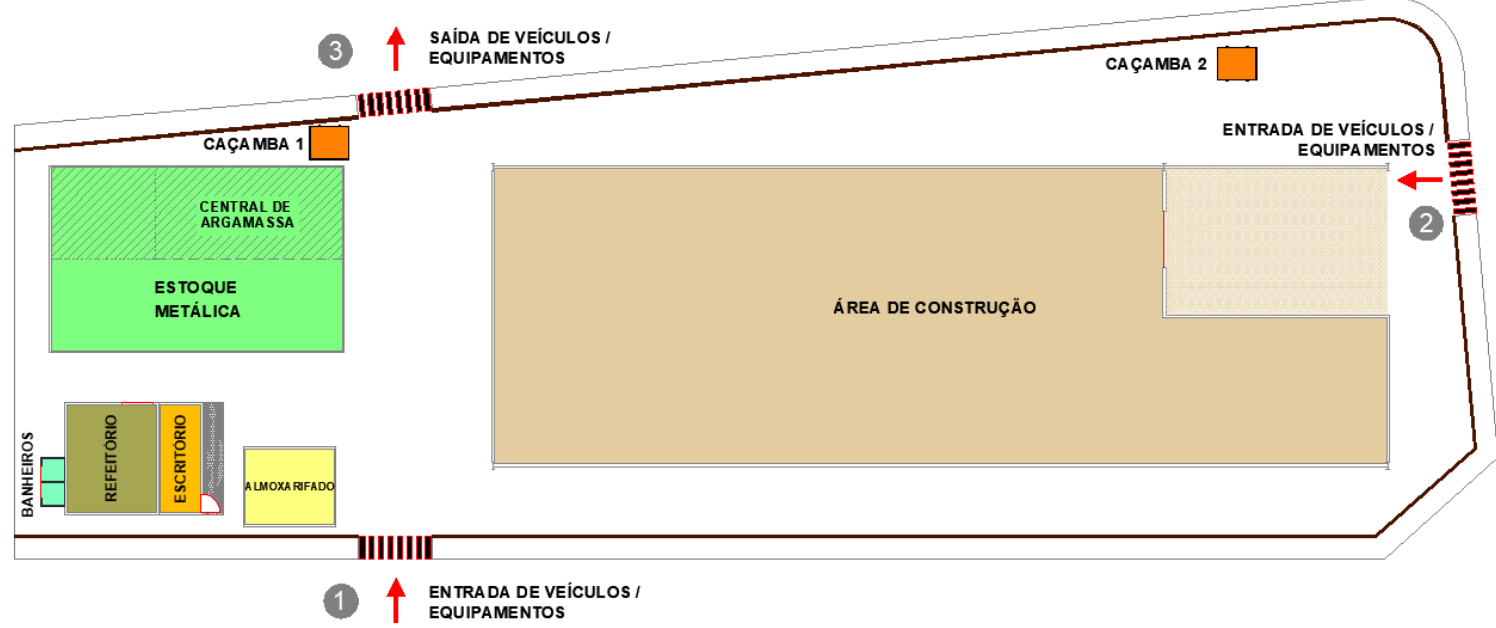

Fonte: Adaptado de Aguiar (2018).

\subsection{Fluxograma de processos}

Os fluxogramas foram desenvolvidos utilizando o método do Diagrama Espaguete. Inicialmente, foi utilizada a plataforma online Lucidchart que possibilita a criação de recursos visuais para traçar os fluxos dos processos. Porém, a plataforma possui recursos limitados no que se refere à obtenção dos valores de distâncias percorridas (comprimento das linhas de fluxo). Logo, a solução encontrada para o traçado do diagrama espaguete foi a utilização do software AutoCAD®, o qual possibilita inserir a planta baixa do canteiro e traçar os fluxos interligando um ponto do canteiro a outro. Após o traçado, os comprimentos das linhas de fluxo foram determinados.

A partir do projeto proposto do canteiro por Aguiar (2018) foram feitas a simulação de fluxo e, posteriormente propostas algumas melhorias no layout para redução da movimentação. Foram analisados os fluxos de entrega de materiais até o local de armazenagem; de transporte dos perfis metálicos - produção a instalação; de transporte do caminhão caçamba para retirada de entulho; de execução da argamassa para alvenaria e revestimento; do caminho percorrido até o banheiro; e do descarte de entulho produzido na obra, sendo esses representados por linhas.

\section{RESULTADOS E DISCUSSÃO}

O diagrama espaguete para o período de execução da obra do galpão, conforme arranjo físico proposto está apresentado na Figura 2. Cada fluxo está representado por uma linha de cor distinta, indicada na legenda, juntamente com os elementos.

A movimentação de equipamentos foi feita pela análise de três processos diferentes. A entrega de materiais, representada pelas linhas pretas, indica a entrada de caminhões para o descarregamento em seus respectivos locais de armazenagem: de materiais diversos da construção no almoxarifado (ponto G) e de perfis de aço no estoque metálica (ponto A). As linhas rosas indicam o transporte de pilares, tesouras e coberturas metálicas, da área de armazenamento até os pontos B, C, D, E e F, onde as peças serão içadas e montadas. 
As linhas em azul claro, indicam o fluxo do caminhão para retirada da caçamba de entulho (pontos $\mathrm{K}$ e L), a partir das entradas do canteiro até a saída.

Quanto a movimentação de pessoas e materiais, também foram analisadas o fluxo durante a execução de três processos. A linha verde indica a distância percorrida por um colaborador, do ponto mais distante da obra (ponto I) até o banheiro existente (ponto J), próximo ao refeitório. A linha azul escuro indica o deslocamento realizado saindo da central de argamassa no ponto $\mathrm{H}$, para realizar a execução da alvenaria e revestimento, até dois pontos analisados: ponto $\mathrm{C}$, na parte superior do galpão e ponto $\mathrm{D}$, o mais afastado da central. A linha laranja indica a mão de obra do descarte de entulho proveniente de resquícios de montagem de materiais metálicos (ponto $\mathrm{M}$ ) até a caçamba 1 (ponto $\mathrm{K}$ ) e resquícios da produção em geral no interior do galpão (ponto $\mathrm{C}$ ) até a caçamba 2 (ponto L).

Figura 2 - Diagrama espaguete dos fluxos analisados conforme layout proposto pelo projeto do canteiro

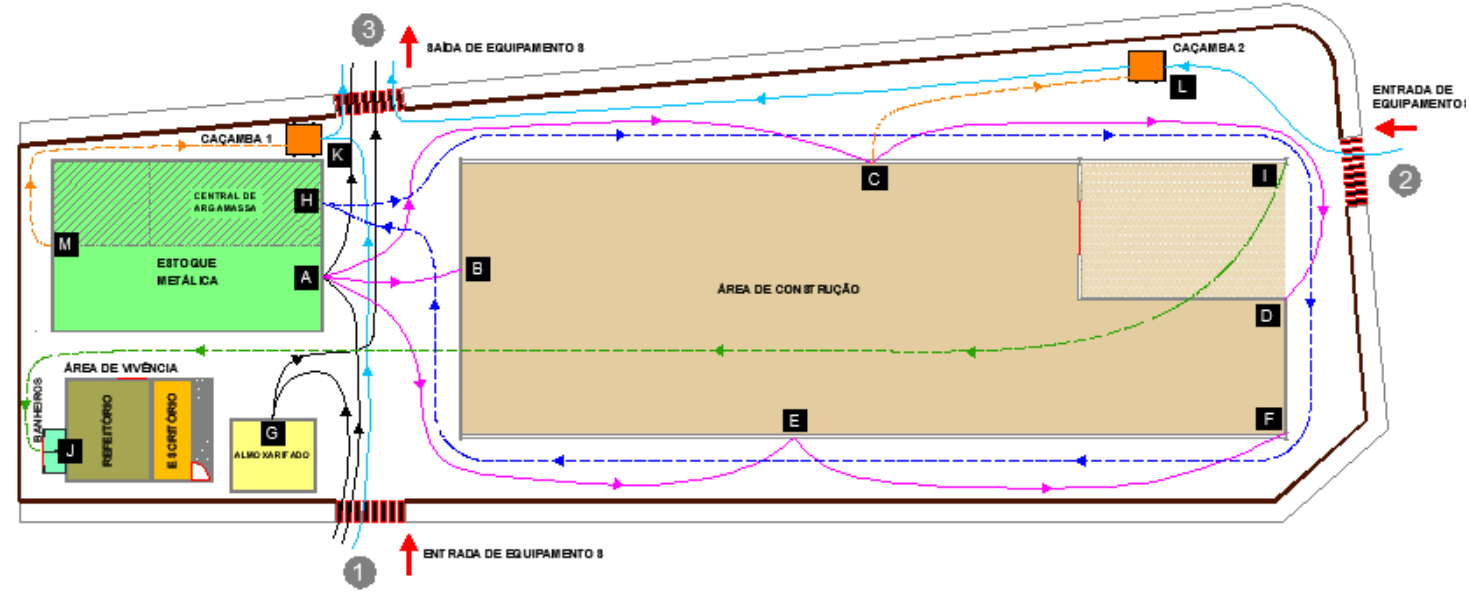

ELEMENTOS DO CANTEIRO

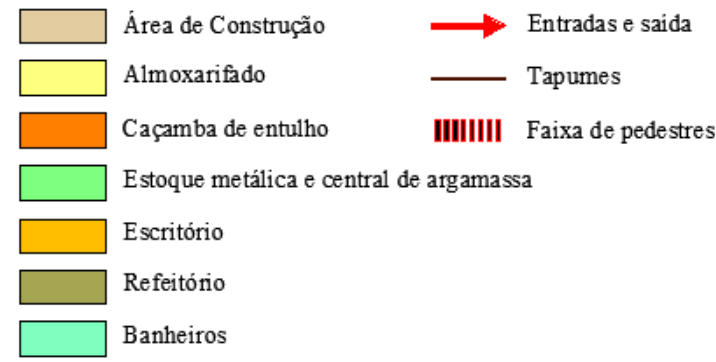

\section{FLUXOS}

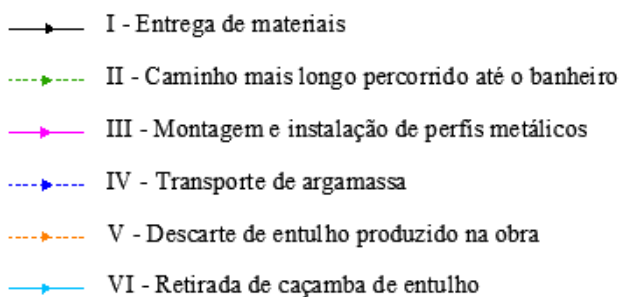

Fonte: Os autores 2021.

Após o traçado das linhas de cada fluxo foram determinadas as distâncias percorridas para cada processo, estas são indicadas no quadro 2. Posteriormente à análise das distâncias, foram observados problemas relacionados ao posicionamento de determinadas áreas de apoio e equipamentos, além de deslocamentos excessivos em certas atividades feitas pelos trabalhadores.

Os equipamentos previstos para serem utilizados na obra compreendem no caminhão de entrega de materiais, caminhão tipo munck responsável pelo içamento e transporte de perfis metálicos, e caminhão para retirada de caçamba de entulho. Em relação ao percurso programado para o caminhão munck, verificou-se que a largura de uma das vias não era suficiente para a sua passagem, visto que o caminhão possui $2,80 \mathrm{~m}$ de largura e a via $2,14 \mathrm{~m}$. Por isso, foi estabelecido que o equipamento percorreria até o ponto $\mathrm{D}$ e o ponto da via estreita (ponto $\mathrm{F}$ ), pois o raio de atuação da lança (deste equipamento em específico) possui alcance máximo horizontal de $12 \mathrm{~m}$. 
Quadro 2 - Distâncias dos fluxos conforme layout proposto para o canteiro de obras

\begin{tabular}{|l|c|c|}
\hline \multicolumn{1}{|c|}{ Fluxo avaliado } & Pontos & Deslocamento (m) \\
\hline \multirow{2}{*}{ Entrega de materiais até o local de armazenagem } & $1-\mathrm{A}-3$ & 34,17 \\
\cline { 2 - 3 } & $1-\mathrm{G}-3$ & 44,84 \\
\hline \multirow{4}{*}{ Transporte dos perfis metálicos - Produção a instalação } & $\mathrm{A}-\mathrm{B}$ & 8,20 \\
\cline { 2 - 3 } & $\mathrm{A}-\mathrm{C}$ & 37,30 \\
\cline { 2 - 3 } & $\mathrm{C}-\mathrm{D}$ & 35,63 \\
\cline { 2 - 3 } & $\mathrm{A}-\mathrm{E}$ & 34,80 \\
\cline { 2 - 3 } & $\mathrm{E}-\mathrm{F}$ & 29,91 \\
\hline \multirow{2}{*}{ Transporte do caminhão caçamba para retirada de entulho } & $1-\mathrm{K}-3$ & 33,21 \\
\cline { 2 - 3 } & $2-\mathrm{L}-3$ & 61,64 \\
\hline \multirow{2}{*}{ Execução da argamassa } & $\mathrm{H}-\mathrm{C}$ & 33,27 \\
\cline { 2 - 3 } & $\mathrm{H}-\mathrm{D}$ & 68,18 \\
\hline Caminho percorrido até o banheiro mais próximo & $\mathrm{I}-\mathrm{J}$ & 83,48 \\
\hline \multirow{2}{*}{ Descarte de entulho produzido na obra } & $\mathrm{C}-\mathrm{K}$ & 17,26 \\
\cline { 2 - 3 } & $\mathrm{M}-\mathrm{L}$ & 20,63 \\
\hline
\end{tabular}

Fonte: Os autores 2021.

Para otimização dos deslocamentos foi feita a alteração da posição de determinadas áreas de apoio e de vivência. A central de argamassa foi levada para o interior do galpão, ficando assim, mais próximo da área de execução da alvenaria e do revestimento. Os blocos cerâmicos também passaram a ser armazenados dentro do galpão, uma vez que se encontrava com o piso industrial executado e a cobertura finalizada. Foram adicionados dois banheiros mais próximos à área de construção. $\mathrm{O}$ arranjo físico otimizado visando a redução de deslocamento na execução da alvenaria e revestimento, considerando o ponto médio de duas fachadas (H-C H-D), e do funcionário até o banheiro é mostrado na Figura 3. Todos os fluxos consideraram um único funcionário para o processo observado, estimando um tempo de operação.

Figura 3 - Fluxos otimizados: execução das argamassas (traçado azul) e deslocamento até o banheiro (traçado verde)

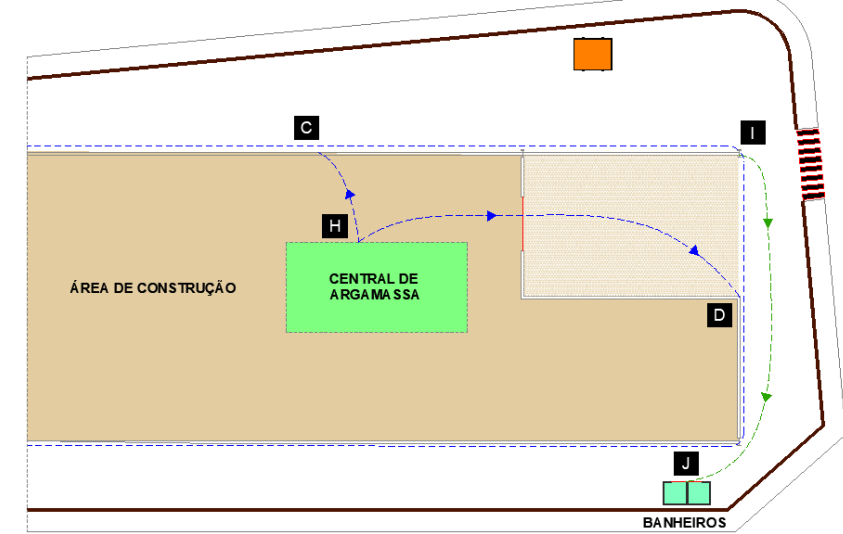

Fonte: Os autores 2021.

Com a central de argamassa mais próxima da área de aplicação, o fluxo de produção de argamassa passou a ser menor comparado com o anterior. $\mathrm{O}$ percurso anteriormente feito entre os pontos $\mathrm{H}$ e $\mathrm{C}$ era de $33,27 \mathrm{~m}$ e do ponto $\mathrm{H}$ ao $\mathrm{D}$ de $68,18 \mathrm{~m}$. Com a mudança no arranjo físico, as distâncias passaram a ser $6,40 \mathrm{~m}$ e 22,61 m, respectivamente. Cabe ressaltar que para a alteração do fluxo foi considerado a execução, visto que inicialmente a mesma não poderia estar localizada na parte interna da edificação devido a montagem da estrutura e, posteriormente, deveria ser deslocada para execução do piso industrial de concreto. Quanto ao deslocamento do funcionário até o banheiro, o acréscimo de um novo banheiro teria um custo a mais, todavia reduziu-se a movimentação do colaborador de $83,48 \mathrm{~m}$ para $21,20 \mathrm{~m}$, diminuindo significativamente o tempo de deslocamento e evitando a fadiga devido à longa distância percorrida dentro do canteiro. Não houve necessidade de alteração do fluxo referente ao descarte de entulhos produzidos na obra, 
dado que o posicionamento das caçambas era próximo as caçambas.

Na Figura 4 é mostrado um comparativo das distâncias percorridas para execução de argamassa (somatório pontos $\mathrm{H}-\mathrm{C}$ e H-D) e de deslocamento até o banheiro (ponto I-J) em relação ao arranjo físico proposto e o otimizado mediante análise dos fluxos obtidos com o diagrama espaguete. Verificou-se uma redução de $77,7 \%$ no fluxo para execução de argamassa (somatório H-C/H-D), e de 74,6\% no deslocamento do funcionário até o novo banheiro instalado após a otimização.

Figura 4 - Comparativo entre o arranjo físico proposto e otimizado considerando os fluxos para a execução de alvenaria e revestimento e até o banheiro

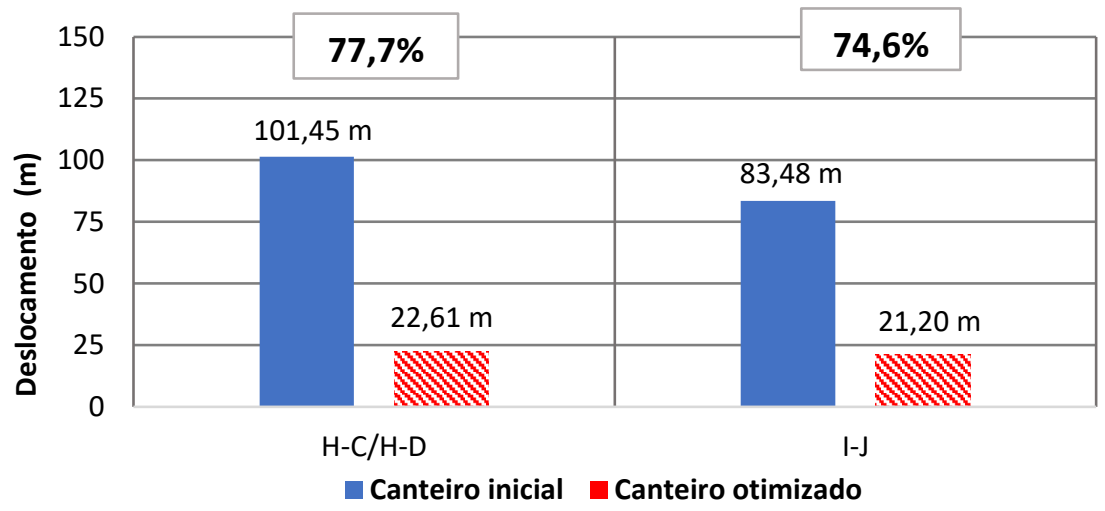

Fonte: Os autores 2021.

\section{CONSIDERAÇÕES FINAIS}

O diagrama espaguete foi uma ferramenta relevante para análise do arranjo físico do canteiro de obras estudado. A análise de fluxos individuais possibilitou verificar os desperdícios de deslocamentos, foi possível reduzir a movimentação de até $77 \%$ com a otimização de um dado fluxo. Esta redução também implicará na diminuição de custo e prazo para a realização do empreendimento. O planejamento do layout do canteiro de obras é uma tarefa importante para garantir a eficiência de um projeto, pois tem um impacto significativo durante a execução do empreendimento. O uso de ferramentas como o diagrama espaguete e o avanço de novas tecnologias tende a corroborar com análise do arranjo físico ainda negligenciado na construção civil.

\section{REFERÊNCIAS}

ABNT. ASSOCIAÇÃO BRASILEIRA DE NORMAS TÉCNICAS. NBR-12284: Área de vivência em canteiro de obras. Rio de Janeiro, 1991.

AGUIAR, E. D. G. Segurança e saúde no trabalho aplicados à construção civil Estudos de casos em Monte Carmelo. Trabalho de Conclusão de Curso (Graduação). Faculdade de Ciências Humanas e Sociais da Fundação Carmelitana Mário Palmério FUCAMP, 2018.

AGUIAR, G. S. G. Inovação em logística de canteiro de obras na construção de edifícios. 2016. Dissertação (Mestrado) - Escola Politécnica da Universidade de São Paulo, São Paulo, 2016. 129 p.

CARVALHO, Y.M.V de; CAMPOS, V.R. Proposta de modelo simplificado para otimização de layout de canteiro. In: SIMPÓSIO BRASILEIRO DE TECNOLOGIA DA INFORMAÇÃO E COMUNICAÇÃO NA CONSTRUÇÃO, 2., 2019, Campinas. Anais... Porto Alegre: Antac, 2019.

COSTA, C. F.; FERREIRA, E. A. M. Projeto de canteiro de obras com o auxílio de ferramentas BIM. In: SIMPÓSIO BRASILEIRO DE TECNOLOGIA DA 
INFORMAÇÃO E COMUNICAÇÃO NA CONSTRUÇÃO, 2., 2019, Campinas. Anais... Porto Alegre: Antac, 2019.

SENDERSKÁ, K.; MARES, A.; VÁCLAV, S. Spaghetti diagram application for workers' movement analysis. U.P.B. Sco. Bull., Series D, v. 79, n. 1, 2017.

ELBELTAGI, E. Construction Site Layout Planning. Saarbrücken: LAP Lambert Academic Publishing, 2014.

HAWARNEH, A. A.; BENDAK, S.; GHANIM, F. Construction site layout planning problem: past, present and future. Expert Systems with Applications, v.168, n. 8, 2021.

HERZAGY, T.; ELBELTAGI, E. Simplified spreadsheet solutions: a model for site layout planning. Cost Engineering, v. 42, 2000, p. 24-30.

KOSKELA, L. CIFE - Center for Integrated Facility Engineering. Application of the new production philosophy to construction, EUA, ed. 72, p. 1-81, agosto 1993.

MELO, R. R. S.; COSTA, D. Uso de veículo aéreo não tripulado (VANT) para inspeção de logística em canteiro de obras. In: SIMPÓSIO BRASILEIRO DE GESTÃO E ECONOMIA DA CONSTRUÇÃO, 9.; ENCONTRO LATINO AMERICANO DE GESTÃO E ECONOMIA DA CONSTRUÇÃO 1, São Carlos. Anais... Porto Alegre: Antac, 2015.

MINISTÉRIO DA ECONOMIA. Norma Regulamentadora n 18 - NR 18: Condições de segurança e saúde no trabalho na indústria da construção. Diário Oficial da União: seção 1, Brasília, DF, ed. 29, p. 21, 10 fev. 2020.

MUTHER, R.; HALES, L. Systematic Layout Planning. 4. Ed. USA: MIRPbooks, 2015.

POLITO, G. Gerenciamento de obras: boas práticas para a melhoria da qualidade e da produtividade. São Paulo: Pini, 2015.

SACRAMENTO, I. C. C.; CAMPOS, V. R.; FERNANDES, V. O.; FERREIRA, E. A. M. Veículo aéreo não tripulado como suporte à gestão de fluxos físicos em canteiro de obras. IN: SIMPÓSIO BRASILEIRO DE GESTÃO E ECONOMIA DA CONSTRUÇÃO, 9; ENCUENTRO LATINO AMERICANO DE GESTIÓN Y ECONOMÍA DE LA CONSTRUCCIÓN, 8., Londrina. Anais... Porto Alegre: Antac, 2019.

SAURIN, T. A.; FORMOSO, C. T. Planejamento de canteiro de obras e gestão de processos. Porto Alegre: Recomendações Técnicas HABITARE, v.3, 2006.

SULE, D. R. Manufacturing Facilities: Location, Planning, and Design. Boca Raton: Third Edition; CRC Press, 2008.

VIANA, C.; SOUZA, C.; PÉREZ, C.; COSTA, D. Análise dos fluxos físicos em canteiro de obras por meio do uso de simulações BIM 4D e com base em algoritmos genéticos. In: SIMPÓSIO BRASILEIRO DE TECNOLOGIA DA INFORMAÇÃO E COMUNICAÇÃO NA CONSTRUÇÃO,1; SIMPÓSIO BRASILEIRO DE GESTÃO E ECONOMIA DA CONSTRUÇÃO, 10., Fortaleza. Anais... Porto Alegre: Antac, 2017.

VIEIRA, H. F. Logística Aplicada à Construção Civil. 1. Ed. São Paulo: PINI, 2006.

TOMMELEIN, I. D. Materials Handling and Site Layout Control. In: Automation and Robotics in Construction, XI, Brighton. Proceedings... Brighton: ISARC,1994.

XU, M.; MEI, Z.; LUO, S.; TAN, Y. Optimization algorithms for construction site layout planning: a systematic literature review. Engineering Construction and Architectural Management, v. 27, n. 8, 2020, p. 1913-1938. 